CZASOPISMO INŻYNIERII LĄDOWEJ, ŚRODOWISKA I ARCHITEKTURY JOURNAL OF CIVIL ENGINEERING, ENVIRONMENT AND ARCHITECTURE

JCEEA, t. XXXIII, z. 63 (4/16), październik-grudzień 2016, s. 505-512

Tomasz STEIDL ${ }^{1}$

Agnieszka SZYMANOWSKA-GWIŻDŻ $\dot{Z}^{2}$

Bożena ORLIK-KOŻDOŃ ${ }^{3}$

Pawel KRAUSE ${ }^{4}$

\title{
ZAWILGOCENIE ŚCIAN BUDYNKU MIESZKALNEGO PO DOCIEPLENIU
}

\begin{abstract}
Autorzy przedstawili wyniki wybranych pomiarów i analizę stanu wilgotnościowego fragmentu docieplonej ściany budynku wielorodzinnego wykonanego w technologii tradycyjnej wykazując, iż uproszczone analizy cieplno-wilgotnościowe wykonane w fazie projektowej, nieuwzględniające początkowego zawilgocenia przegrody powoduje znaczące zawilgocenia i zagrzybienia ściany od strony wewnętrznej. Uszkodzenia takie są bardzo uciążliwe dla mieszkańców budynków poddanych termomodernizacji.
\end{abstract}

Słowa kluczowe: docieplanie budynków, zawartość wilgoci, system ETICS

\section{Wprowadzenie}

Docieplanie budynków mieszkalnych od kilku lat traktuje się jako typowy zabieg termomodernizacyjny, zarówno w zakresie projektowania jak i wykonawstwa. Wady lub uszkodzenia powstające w budynkach ocieplonych kojarzy się na ogół z wadliwym wykonawstwem, zamianą materiałów na inne niż projektowane lub rzadziej z typowymi błędami projektowymi. Szczegółowe wytyczne dotyczące projektowania, wykonawstwa i odbioru robót budowlanych w zakresie stosowanie metody lekkiej mokrej, obecnie znanej jako ETICS, znajdują się w instrukcji ITB 447/2009. Wytyczne te wydają się być wystarczające do poprawnego projektowania i wykonania oraz odbioru robót dla budynków mieszkalnych. Występujące coraz częściej przypadki wzrostu wilgotności ścian

1 Tomasz Steidl, Politechnika Śląska, Katedra Budownictwa Ogólnego i Fizyki Budowli, ul. Akademicka 5, 44-100 Gliwice, tel. 32237 2303; Tomasz Steidl@polsl.pl

2 Agnieszka Szymanowska-Gwiżdż; Politechnika Śląska, Katedra Budownictwa Ogólnego i Fizyki Budowli, ul. Akademicka 5, 44-100 Gliwice, tel. 32 237 2303; Agnieszka.Szymanowska-Gwizdz@ polsl.pl

${ }^{3}$ Bożena Orlik-Kożdoń; Politechnika Śląska, Katedra Budownictwa Ogólnego i Fizyki Budowli, ul. Akademicka 5, 44-100 Gliwice, tel. 32237 2303; Bozena.Orlik@polsl.pl

${ }^{4}$ Paweł Krause; Politechnika Śląska, Katedra Budownictwa Ogólnego i Fizyki Budowli, ul. Akademicka 5, 44-100 Gliwice, tel. 32237 2303; Pawel.Krause@ polsl.pl 
zewnętrznych budynków, a w konsekwencji zagrzybienia, w krótkim okresie po wykonaniu docieplenia nasuwają pytanie czy i jakie badania lub obliczenia należałoby wykonać aby uniknąć pojawiania się takich zjawisk, zwłaszcza w budynkach mieszkalnych (rys. 1).

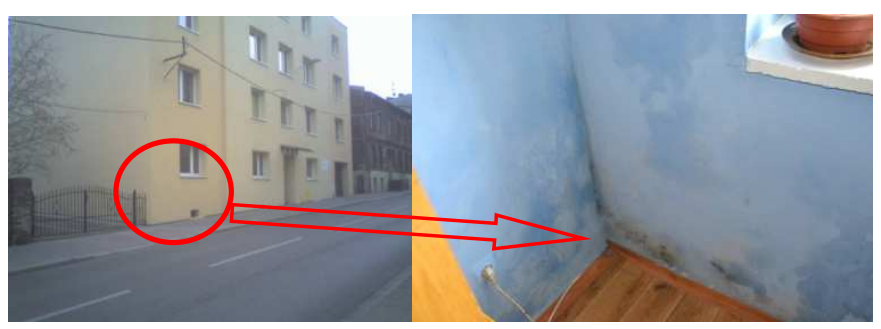

Rys. 1. Zawilgocenie i zagrzybienie budynku po dociepleniu

Fig. 1. Moisture and fungus portion of the building after warming

\section{Analizowany obiekt i występujące w nim uszkodzenia}

Przedmiotowy budynek jest całkowicie podpiwniczony, posiada 4 kondygnacje nadziemne. Budynek został wykonany w technologii tradycyjnej z elementów drobnowymiarowych (cegły pełnej). Stolarka okienna w części mieszkalnej w znacznej części wymieniona na nową PVC. Budynek docieplony w październiku 2014 r. W ramach prac dociepleniowych wykonano następujące prace które polegały na dociepleniu ściany $30 \mathrm{~cm}$ poniżej gruntu do górnej linii cokołu styropianem EPS 100 gr. 14,0 cm oraz dociepleniu ściany piwnicy na elewacji północnej do fundamentów styropianem EPS 100 gr. 14,0 cm [5]. Pierwsze widoczne zawilgocenia wystąpiły w mieszkaniach parteru w krótkim okresie po termomodernizacji (grudzień 2014 r.). Zawilgocenia występowały w mieszkaniach położonych na parterze w tym głównie w części narożnej budynku - rys. 2.
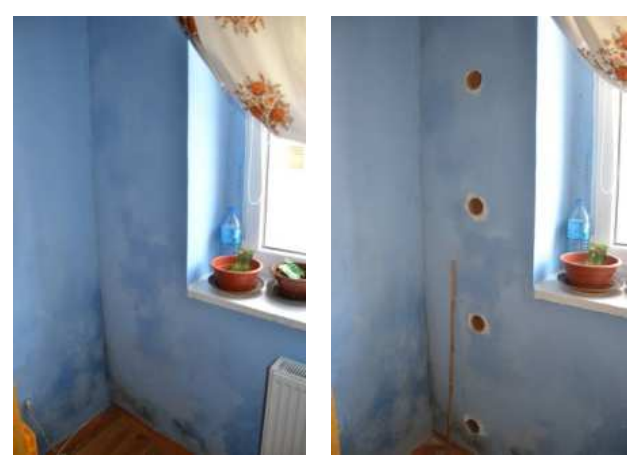

Rys. 2. Zawilgocenia ścian parteru po dociepleniu, z miejscem pobrania próbek

Fig. 2. Moisture on the walls of the ground floor warming 


\section{Badania i analizy przyczyn zawilgocenia}

Celem ustalenia przyczyn powstałych zawilgoceń ustalono plan pomiarów w zakres, których przyjęto. następujące działania: - pomiary wilgotności ścian metodą bezinwazyjną, - pomiary wilgotności próbek pobranych w miejscach widocznych zawilgoceń, - pomiary wybranych parametrów mikroklimatu pomieszczeń.

\subsection{Pomiary wilgotności metodą bezinwazyjną}

Pomiary wykonano za pomocą przyrządu pomiarowego Testo $635-2$ z sondą do pomiaru wilgotności materiałowej. Jest to przyrząd do pomiaru temperatury wilgotności powietrza, równowagi wilgotności materiału. Dokładność pomiarowa $+/-1 \%$. Badania przeprowadzano w grudniu $2014 \mathrm{r}$. Wykonane pomiary wykazały, iż na powierzchni wewnętrznej w miejscach pobranych próbek (miejsca wilgotnych plam) wilgotność tynku przekraczała $20 \%$.

\subsection{Pomiary wilgotności pobranych próbek}

W celu określenia stopnia zawilgocenia ścian parteru w najbardziej zawilgoconym mieszkaniu od strony pomieszczeń pobrano cztery próbki ze ściany zewnętrznej (zlokalizowanej od strony zachodniej) (rys. 3 i 4). Próbki pobrano kolejno z wysokości: $0,20 \mathrm{~m}, 0,70 \mathrm{~m}, 1,20 \mathrm{~m}, 1,70 \mathrm{~m}$ od podłogi. Pobrane próbki zbadano laboratoryjnie metodą wagowo-suszarkową. Dokładność pomiarowa $+/-0,01 \%$.

W tabeli 1 przedstawiono wyniki pomiarów wilgotności masowej próbek, $\mathrm{w}$ której $\mathrm{m}_{\mathrm{w}}[\mathrm{g}]$ - masa próbki w stanie nasyconym wodą; $\mathrm{m}_{\mathrm{s}}[\mathrm{g}]$ - masa próbki w stanie suchym; w [\%] - wilgotność masowa próbki.
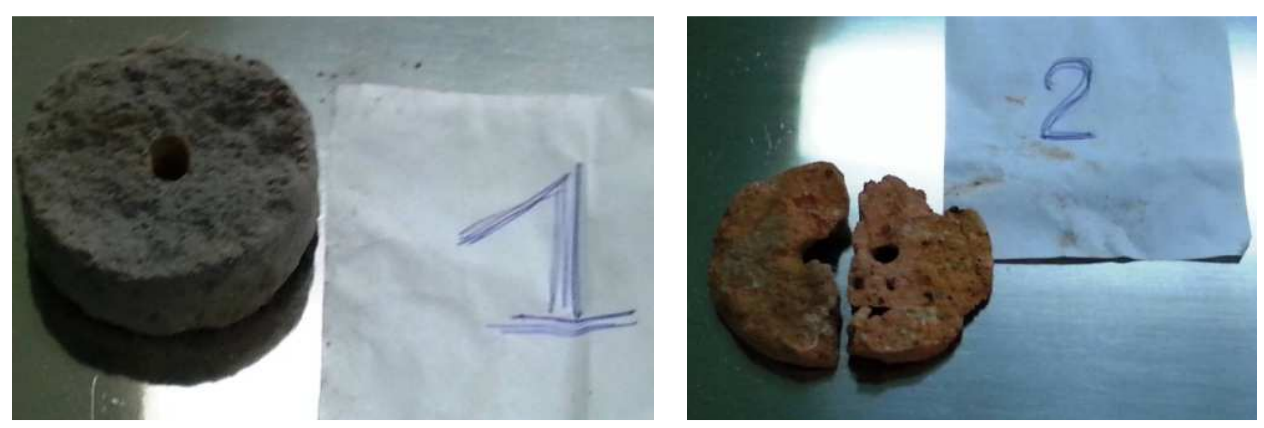

Rys. 3, 4. Próbka nr 1 i 2 pobrana ze ściany zewnętrznej od wewnątrz w rejonie naroża

Fig. 3, 4. Sample No. 1 and 2, taken from the outer wall on the inside in the region of the corner 
Tabela 1. Zestawienie wyników pomiarów

Table 1. Summary of the results of the measurements

\begin{tabular}{|c|c|c|c|c|c|c|}
\hline \multirow{2}{*}{ Próbka } & \multicolumn{3}{|c|}{ Ceramika } & \multicolumn{3}{c|}{ Tynk } \\
\cline { 2 - 7 } & $\mathrm{m}_{\mathrm{w}}[\mathrm{g}]$ & $\mathrm{m}_{\mathrm{s}}[\mathrm{g}]$ & $\mathrm{w}[\%]$ & $\mathrm{m}_{\mathrm{w}}[\mathrm{g}]$ & $\mathrm{m}_{\mathrm{s}}[\mathrm{g}]$ & $\mathrm{w}[\%]$ \\
\hline 1 & 110,00 & 106,20 & 3,58 & 49,00 & 44,20 & 10,86 \\
\hline 2 & 41,00 & 35,30 & 16,15 & 17,00 & 15,10 & 12,58 \\
\hline 3 & 60,00 & 55,75 & 7,62 & 28,00 & 27,50 & 1,82 \\
\hline 4 & 56,00 & 50,85 & 10,13 & 81,00 & 75,45 & 7,36 \\
\hline
\end{tabular}

\subsection{Monitoring wilgotności i temperatury}

Monitoring temperatury i wilgotności względnej powietrza w przedmiotowym mieszkaniu przeprowadzono za pomocą przenośnego rejestratora temperatury i wilgotności. Datalogger ST-171 (rys. 5) rejestruje temperaturę w zakresie od -40 do $70^{\circ} \mathrm{C}$ z rozdzielczością $0.1^{\circ} \mathrm{C}$ i dokładnością podstawową $\pm 1 \%$ oraz wilgotność względną powietrza w zakresie od 0 do $100 \%$ z rozdzielczością $0,1 \%$ dzięki wbudowanym czujnikom temperatury i wilgotności. Podczas prowadzenia pomiarów nie ma możliwości odczytu bieżących wyników przez użytkownika mieszkania, co zabezpiecza przed niepożądanymi zachowaniami w zakresie eksploatacji pomieszczeń mieszkalnych, odbiegającymi od typowych.

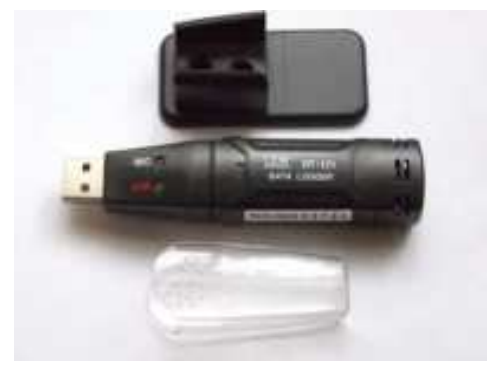

Rys. 5. Datalogger typu ST-171

Fig. 5. Data Logger ST-171

W mieszkaniu zamontowano cztery rejestratory na wysokości $1 \mathrm{~m}$ powyżej poziomu posadzki, we wszystkich czterech pomieszczeniach mieszkalnych. Próbkowanie prowadzono co godzinę. Przykładowy rejestrator przedstawiono na powyższym zdjęciu. Dane $\mathrm{z}$ odczytów przedstawione są $\mathrm{w}$ formie wykresów i tabeli $\mathrm{z}$ wartościami maksymalnymi (max), minimalnymi (min) i wartością średnią (średnia). Po zakończeniu planowanego cyklu pomiarów wyniki przenosi się z rejestratora bezpośrednio do komputera. Poniżej zaprezentowano przykładowe zestawienie wyników dla jednego z wybranych pomieszczeń mieszkalnych (pokój sypialny). Całkowity czas trwania pomiarów od: 11.12.2014 do: 09.01.2015. Początek pomiaru: 11.12.2014 godz. 10:20:42. Koniec pomiaru: 
09.01.2015 godz. 09:20:42. Łącznie ilość pomiarów wybranych jako reprezentatywne: 696 godzin $=29$ dni pomiarowe. Wyniki zebrano $\mathrm{w}$ formie graficznej na rys. 6, całość w tab. 2.

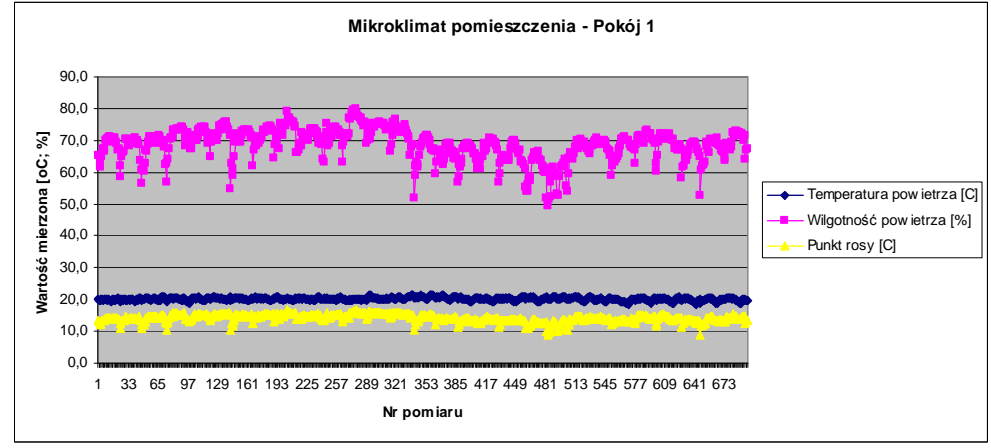

Rys. 6. Zestawienie wyników pomiarów temperatury i wilgotności

Fig. 6. Summary of the results of measurements of temperature and humidity

Tabela 2. Zestawienie wartości max., min. i średniej dla mierzonych parametrów Table 2. Statement of the value of the max, min and average the measured parameters

\begin{tabular}{|l|c|c|c|}
\cline { 2 - 4 } \multicolumn{1}{c|}{} & $\begin{array}{c}\text { Temperatura po- } \\
\text { wietrza }\left[{ }^{0} \mathrm{C}\right]\end{array}$ & $\begin{array}{c}\text { Wilgotność po- } \\
\text { wietrza [\%] }\end{array}$ & $\begin{array}{c}\text { Temperatura } \\
\text { punktu rosy }\left[{ }^{0} \mathrm{C}\right]\end{array}$ \\
\hline Min. & 18,6 & 49,2 & 9,0 \\
\hline Max. & 21,5 & 80,1 & 16,7 \\
\hline Średnia & 20,2 & 68,6 & 14,1 \\
\hline
\end{tabular}

Analizując uzyskane wyniki postawiono hipotezę, iż przyczyną tak dużego wzrostu wilgotności ściany są prawdopodobnie dwa czynniki, których wzajemne działanie dało końcowy efekt:

1) niewłaściwa eksploatacja pomieszczeń,

2) początkowe duże zawilgocenie ściany zewnętrznej i ściany piwnicy, zarówno części, która jest zagłębiona w gruncie jak fragmentu wystającego ponad otaczający teren (przed wykonaniem robót ociepleniowych).

\section{Obliczenia i symulacje przepływu ciepła i wilgoci}

Celem potwierdzenia lub zaprzeczenia postawionej tezie wykonano uproszczone obliczenia cieplno-wilgotnościowe oraz symulacje przepływ ciepła i wilgoci przez fragment przegrody zewnętrznej. 


\subsection{Obliczenia uproszczone}

Jako obliczenia uproszczone wykonano model jednowymiarowy zgodnie z PN -EN -13877 [1]. Na potrzeby obliczeń przyjęto parametry klimatu zewnętrznego najbliższe dla lokalizacji stanowiska badawczego - stacja meteo Katowice. Wpływ klimatu wewnętrznego uwzględniono jako pomieszczenie klasy 3 - mieszkanie średnio zagęszczone o stałej temperaturze eksploatacji ti=21 ${ }^{\circ} \mathrm{C}$. Wilgotność wewnętrzną przyjęto jako średni wynik z pomiarów tj. $\varphi \mathrm{i}=64,5 \%$.

Dane materiałowe na podstawie bazy danych programu tj. pochodzących z PN-EN-ISO 6946 : 1999 r. [2]. Przeprowadzone obliczenia wykazały:

- brak kondensacji między warstwowej w ciągu całego roku;

- brak kondensacji powierzchniowej;

- współczynnik przenikania ciepła $\mathrm{U}_{\mathrm{c}}=0,217 \mathrm{~W} /\left(\mathrm{m}^{2} \mathrm{~K}\right)<\mathrm{U}_{\max }=0,25 \mathrm{~W} /\left(\mathrm{m}^{2} \mathrm{~K}\right)$.

Wyniki obliczeń dla najzimniejszego miesiąca (styczeń) przedstawiono w postaci graficznej - wykres prężności pary wodnej pokazano na rys. 7.

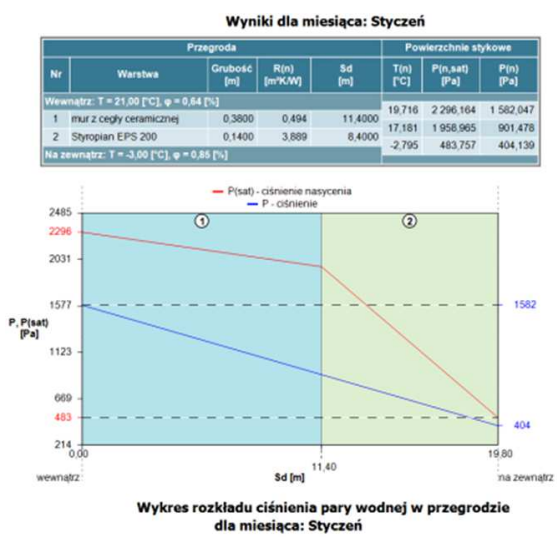

Rys. 7. Graficzna prezentacja wyników obliczeń zgodnie z PN-EN-13877 [1], brak kondensacji w przekroju przegrody

Fig. 7. Graphical presentation of the results of calculation in accordance with PN-EN-13877 [1], no condensation in the cross section of the partition

\subsection{Symulacja przepływu ciepła i wilgoci}

Symulację przepływu ciepła i masy wykonano dla detalu budowlanego, w którym uwzględniono: fragment ściany zewnętrznej, fragment ściany nadziemia, fragment stropu nad piwnicą uwzględnieniem. Obliczenia wykonano w programie WUFI ${ }^{@}$ 2D [3], przy następujących założeniach: klimat zewnętrzny - Katowice; klimat wewnętrzny sinusoidalny, zbliżony do pomierzonego, czas symulacji od końca docieplenia (od 10.2014, do momentu badania 12.2014), wilgotność początkowa ściany ceglanej $4 \%$. Model obliczeniowy wraz z siatką MES pokazano na rys. 8. Wyniki zaprezentowano w formie graficznej rys. 9. 
1-ściana zewnętrzna

2-ocieplenie - stropian +tynk zewnętrzny

(cieńkowarstwowy)

3-ściana piwnicy

4-ocieplenie ściany piwnicy (styropian)

5-strop nad piwnicą

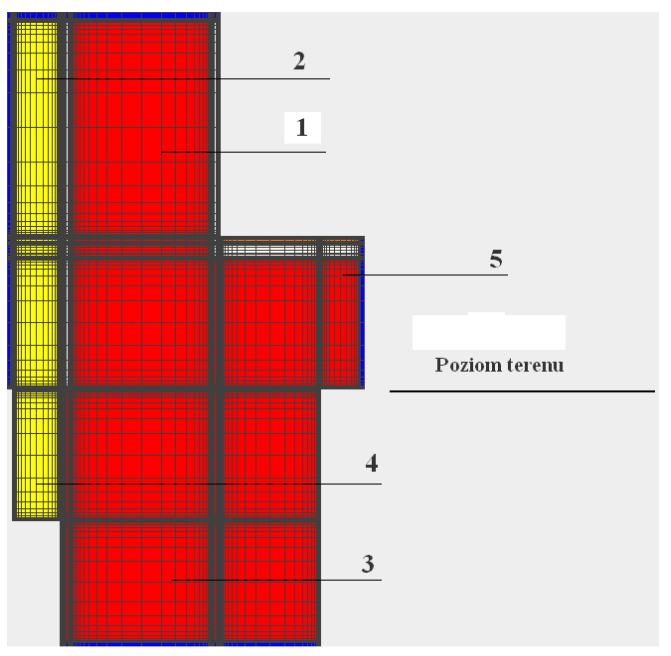

Rys. 8. Model MES analizowanego fragmentu połączenia ściany ze stropem i ścina piwnicy

Fig. 8. FEM -model of the analyzed portion of the connection wall to the ceiling and cuts the basement

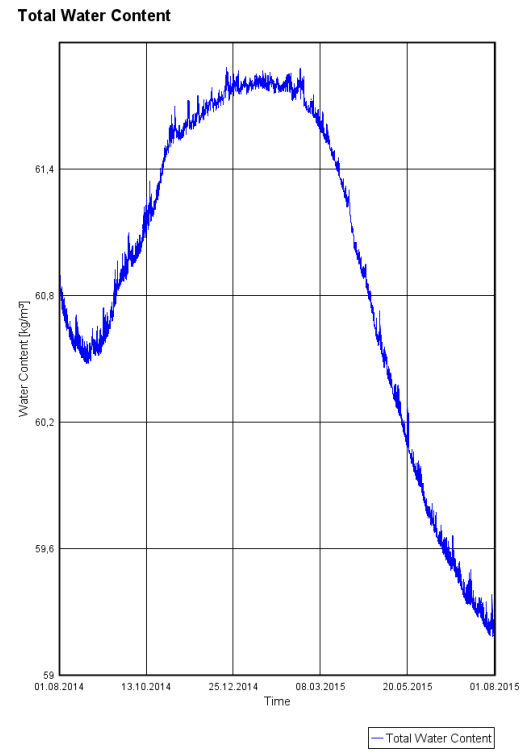

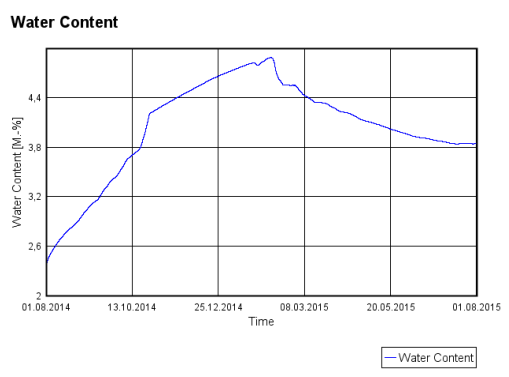

Water Content

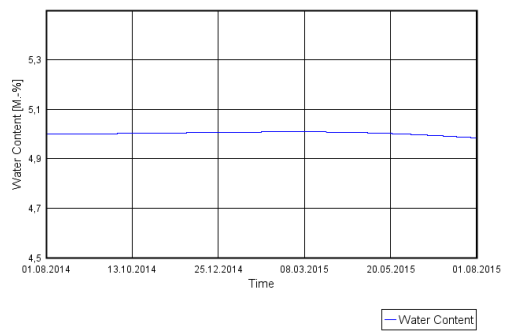

Rys. 9. Zmiany w czasie całkowitej zawartość wody w badanym fragmencie

Fig. 9. The variation in time of the total water content in the analyzed fragment 


\title{
5. Podsumowanie i wnioski
}

Powstałe $\mathrm{w}$ przedmiotowym budynku zawilgocenia ścian związane są z niewłaściwą eksploatacją mieszkań, a także z brakiem uwzględnienia przez projektanta faktu, iż ściany przed dociepleniem mogą być znacznie zawilgocone. Wydaje się być zatem koniecznym aby projektant określił w projekcie ocieplenia maksymalną dopuszczalną wilgotność ściany zewnętrznej przed jej dociepleniem. Badanie takie jest stosunkowo proste i mogłoby być wykonane przed rozpoczęciem robót ociepleniowych np. przez kierownika budowy lub inspektora nadzoru inwestorskiego. Istniejące wytyczne zawarte w Instrukcji 447/2009, dotyczące systemów izolacji cieplnej typu ETICS, należałoby uzupełnić o określanie dopuszczalnej wilgotności zewnętrznej przegrody budowlanej poddawanej ociepleniu. Dodatkowym wnioskiem wypływającym z przedstawionego przypadku jest fakt, iż uproszczone metody określania kondensacji międzywarstwowej są w sposób znaczący niewystarczające i odbiegające od rzeczywistości, a wielu przypadkach prowadzą do uzyskania błędnych wyników.

\section{Literatura}

[1] PN-EN ISO 13788:2003: Cieplno-wilgotnościowe właściwości komponentów budowlanych i elementów budynku. Temperatura powierzchni wewnętrznej konieczna do uniknięcia krytycznej wilgotności powierzchni i kondensacja międzywarstwowa. Metody obliczania.

[2] PN-EN ISO 6946:1999: Komponenty budowlane i elementy budynku. Opór cieplny i współczynnik przenikania ciepła. Metoda obliczania. Załącznik krajowy NC: wartości obliczeniowe właściwości fizycznych niektórych materiałów, wyrobów i komponentów budowlanych.

[3] Krause P., Steidl T. "Opinia techniczna dotycząca występującego zawilgocenia i warunków eksploatacji mieszkania zlokalizowanego w budynku wielorodzinnym w Chorzowie". STEKRA sp. z.o.o. Mikołów 2014.

\section{ANALYSIS OF THE STATE OF MOISTURE FOR BRICK WALLS WITH INTERNAL INSULATION}

\author{
S u m m a r y \\ The authors present the analysis of moisture wallsportion of the building after warming \\ showing that a simplified analysis of heat and moisture in the design phase and no consideration of \\ the initial moisture septum causes significant moisture and mildew on the inside wall. Such inju- \\ ries are very painful for the people of insulated buildings.
}

Keywords: internal insulation, hygrothermal processes, water content, brick wall

DOI: $10.7862 / r b .2016 .294$

Przestano do redakcji: 29.05.2016 $r$.

Przyjęto do druku: 20.12.2016 r. 